\title{
Technical Report on the Modification of 3-Dimensional Non-contact Human Body Laser Scanner for the Measurement of Anthropometric Dimensions: Verification of its Accuracy and Precision
}

\author{
Akram Sadat Jafari Roodbandi ${ }^{1}$, Hamid Naderi², Naser Hashenmi-Nejad ${ }^{3}$, Alireza Choobineh ${ }^{4}$, Mohammad \\ Reza Baneshi ${ }^{5}$, Vafa Feyzi ${ }^{6}$ \\ ${ }^{1}$ School of Public Health, Occupational Health Department, Bam University of Medical Sciences, Bam, Iran \\ ${ }^{2}$ BSc of Computer Enginnering, Ferdoos Payam Noor University, Ferdoos, Iran \\ ${ }^{3}$ School of Public Health, Occupational Health Department, School of Public Health, Kerman University of Medical Sciences, \\ Kerman, Iran \\ ${ }^{4}$ Research Center for Health Sciences, Institute of Health, Shiraz University of Medical Sciences, Shiraz, Iran \\ ${ }^{5}$ Research Center for Modeling in Health, Institute for Futures Studies in Health, Kerman University of Medical Sciences, \\ Kerman, Iran \\ ${ }^{6} \mathrm{MSc}$ of Occupational Health, Dezful University of Medical Sciences, Dezful, Iran
}

\section{*Correspondence to \\ Alireza Choobineh, PhD; Research Center for Health Sciences, Institute of Health, Shiraz University of Medical Sciences, Shiraz, Iran. Tel: +98-9171184450; Fax: +98-7137260225 Email: alrchoobin@sums.ac.ir}

Published online 8 January 201

\begin{abstract}
Introduction: Three-dimensional (3D) scanners are widely used in medicine. One of the applications of 3D scanners is the acquisition of anthropometric dimensions for ergonomics and the creation of an anthropometry data bank. The aim of this study was to evaluate the precision and accuracy of a modified 3D scanner fabricated in this study.

Methods: In this work, a 3D scan of the human body was obtained using DAVID Laser Scanner software and its calibration background, a linear low-power laser, and one advanced webcam. After the 3D scans were imported to the Geomagic software, 10 anthropometric dimensions of 10 subjects were obtained. The measurements of the 3D scanner were compared to the measurements of the same dimensions by a direct anthropometric method. The precision and accuracy of the measurements of the 3D scanner were then evaluated. The obtained data were analyzed using an independent sample t test with the SPSS software.

Results: The minimum and maximum measurement differences from three consecutive scans by the 3D scanner were $0.03 \mathrm{~mm}$ and $18 \mathrm{~mm}$, respectively. The differences between the measurements by the direct anthropometry method and the $3 \mathrm{D}$ scanner were not statistically significant. Therefore, the accuracy of the 3D scanner is acceptable.

Conclusion: Future studies will need to focus on the improvement of the scanning speed and the quality of the scanned image.

Keywords: Anthropometry; Three-dimensional; Technical report; Three-dimensional laser scanner; Accuracy and precision of measurement.
\end{abstract}

\section{Introduction}

Three-dimensional (3D) whole body scanners have become common and useful tools for obtaining and recording anthropometric data in the last decade. ${ }^{1}$ Anthropometry, which records the surface anatomy of the human body, is a branch of physical anthropology. In order to design an appropriate ergonomic environment, the measurement of the specific dimensions of the body, such as height, width, depth, distances, perimeters, and curves, is necessary. ${ }^{2,3}$

Many new and indirect anthropometric methods have been widely used owing to their high speed, ease of administration, and the provision of accurate information with high quality, and have supplemented or replaced traditional manual methods. ${ }^{4,5}$ Anthropometric data from new methods, such as laser scanning, are collected

Please cite this article as follows: Jafari Roodbandi AS, Naderi H, Hashenmi-Nejad H, Choobineh A, Baneshi MR, Fayzi V. Technical report on the modification of 3-dimensional non-contact human body laser scanner for the measurement of anthropometric dimensions: verification of its accuracy and precision. J Lasers Med Sci. 2017;8(1):22-28. doi:10.15171/jlms.2017.05. 
automatically, rapidly, and reliably, without human intervention and contact with the subject. New anthropometric techniques are easy to use, non-invasive, low-cost, reliable, fast, and sufficiently precise. They can also store information in digital format and provide an archive to be used for further studies, or recall other data without the need of people participation. ${ }^{6,7}$

$3 \mathrm{D}$ laser scanners are widely used in various fields, such as ergonomics, industrial design, textile industry, reverse engineering, medicine structural engineering, forestry, urban development, etc. ${ }^{8-14}$

Compared to other anthropometric methods, the use of scanners can be regarded as optimized, owing to three factors: time, cost, and accuracy. ${ }^{15,16}$

$3 \mathrm{D}$ scanners measure the third dimension $(z)$, which is the depth of a point on the two dimensions (" $x$ " and " $y$ "), and it is termed voxel (volumetric pixel). ${ }^{17}$

Laser triangulation is a common scanning method. The method is based on a laser light, a couple charged device (CCD) camera, and a calibration page, where the linear laser light becomes the light source and the camera detects the movement of light on the surface of the body. It works by determining two angles and one side of the triangle (Figure 1). ${ }^{18}$

Millions of points can be obtained within a few seconds in

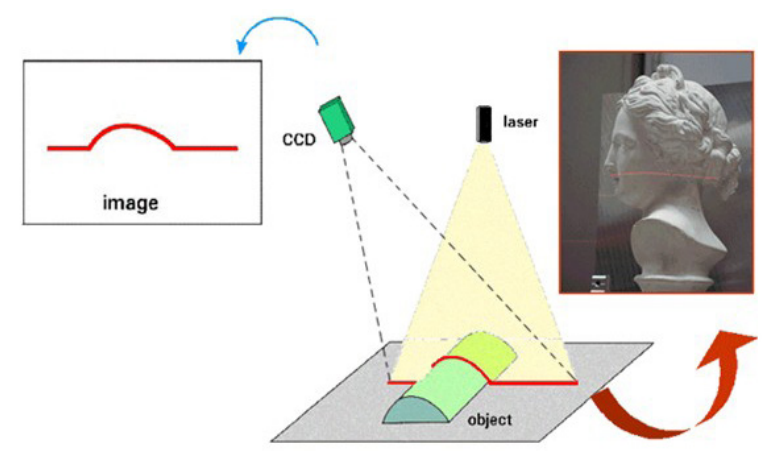

Figure 1. Schematic of the Location of the Camera, Laser, and the Object in 3D Scanners With the Laser Triangulation Method.
3D technology. Consequently, this can lead to the creation of an image with a large number of details and high accuracy computer models. It also creates the possibility of deriving information such as the shape, distance, perimeter, and volume of the object. ${ }^{19}$ In the field of ergonomics, 3D scanners are focused on anthropometry, the size and shape of the human body, human digital models, and work environment simulations in order to quickly collect information without the need for human assistance. ${ }^{20-22}$

Since 1985, many systems that use white light, laser light, and shadows to collect data points from the human body have been developed. In the last 20 years, the technology of human body 3D scanners has witnessed a significant growth. Numerous studies have been conducted to solve the problems and flaws of such scanners. Currently, there are several large companies, such as CAESAR, Cyberware, $[\mathrm{TC}]^{2}$, SYMCAD, Witronic, and Wicks \& Wilson, that use different technologies in manufacturing scanners. As a result, the final output of the scanners of each brand is to some extent different from the others. ${ }^{23-30}$

Although Iran has been researching industrial scanners for some time, ${ }^{31}$ no study on human body scanners and their application in engineering anthropometry has been conducted. Therefore, the aim of this study was to assess the validity and reliability of human body scanners.

\section{Methods}

The DAVID laser scanner possesses a software that can be used to produce $3 \mathrm{D}$ scans. In this study, we used the trial DAVID Laser Scanner software version 2.6.3. In addition to the DAVID laser scanner software, background calibration, a linear laser, and an advanced webcam were used in this study.

Background Calibration in DAVID Laser Scanner Software

According to the instructions of the DAVID laser scanner, the calibration background was installed at an exact 90 degree angle. In this software package, it is possible to set

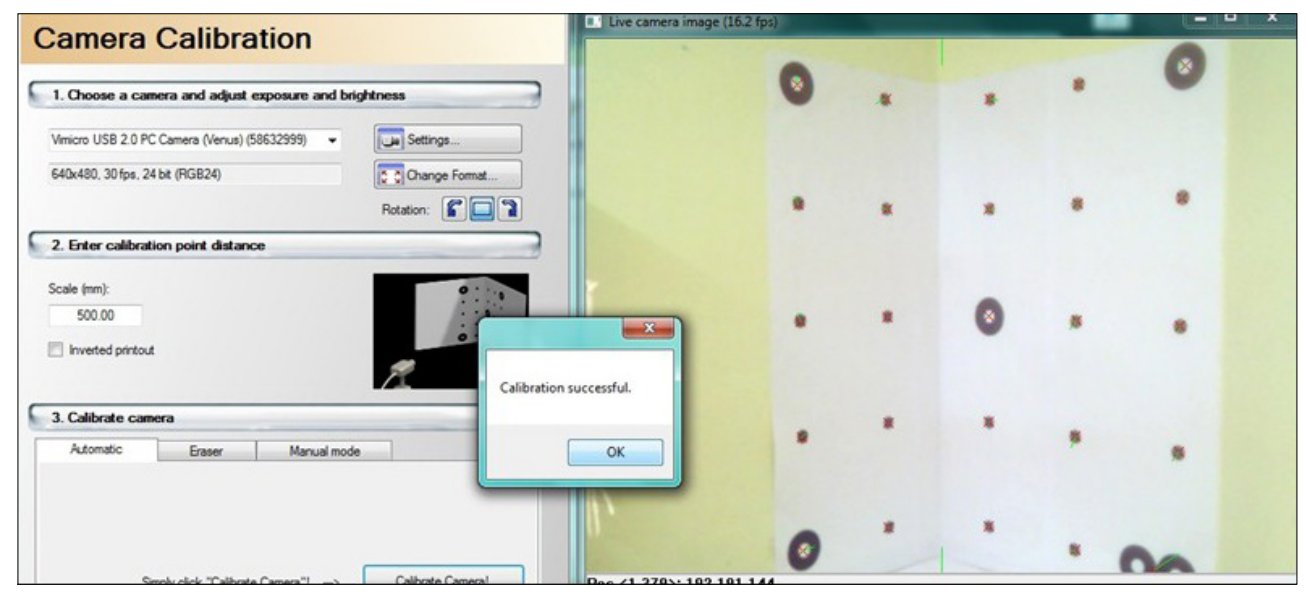

Figure 2. Left Side: Calibration Settings of the DAVID Laser Scanner Software. Right Side: Calibration Background Recorded by the Webcam and Displayed by the Software. 
the calibration software background up to A1 size. The distance between points was changed to $50 \mathrm{~cm}$ and a 2 $\mathrm{m} \times 2 \mathrm{~m}$ background was created in order for the scanner to be compatible with the standard human size. The background was drawn in AutoCAD software and printed using a high precision plotter (Figure 2).

\section{Webcam}

A Logitech webcam pro 9000 with Carl Zeiss optics, autofocus and video with up to 30 frames per second was used in the study. The webcam was placed at a distance of about $2.5 \mathrm{~m}$ across the bisector of the calibration background angle. The webcam was connected to a computer equipped with the DAVID Laser Scanner software.

Steps of Construction of 3D Non-contact Human Body Laser Scanner

\section{First Step: Camera Calibration}

The webcam was enhanced with the DAVID laser scanner software, and all 25 points were visible within the camera's field of view; the actual distance between points on the calibration background $(50 \mathrm{~cm})$ was defined with the DAVID software (Figure 2).

Second Step: Scanning

In the second step, the laboratory lights were turned off and any remaining light removed by covering the windows. The linear low-power laser was turned on. The la- ser power was seen as a continuous, horizontal gleaming red line with no deviation from the horizon on the software screen. At this stage, by moving the laser source by hand on the support, the linear laser line was slowly and accurately moved in the vertical direction (up and down). A 3D file was simultaneously created as the laser was vertically moved over the object (Figure 3 ). This file could be stored in .ply or .obj formats (Figure 4).

Third Step: Measurement of Dimensions

In the third step, the output file of the DAVID laser scanner software was imported into a software that could handle the .ply or .obj formats. It should be noted that not all software packages can read these data formats. In other words, if you try to open any of such formats with irrelevant software, it would be like when you attempt to open a video file (such as .mp4) with Microsoft Office Word or Adobe Reader. The Geomagic software can read the output of the DAVID laser scanner software. The units of the dimensions in the imported file can be displayed in microns, millimeters, centimeters, meters, or kilometers. According to the available physical dimensions and the application of these dimensions in anthropometry, the millimeter scale was chosen. The curvature, diameter, volume, length, width, perimeter, and area are some of the parameters available from Geomagic (Figure 5).

By holding the mouse at any point on the $3 \mathrm{D}$ model in the Geomagic software, it was possible to obtain the co-

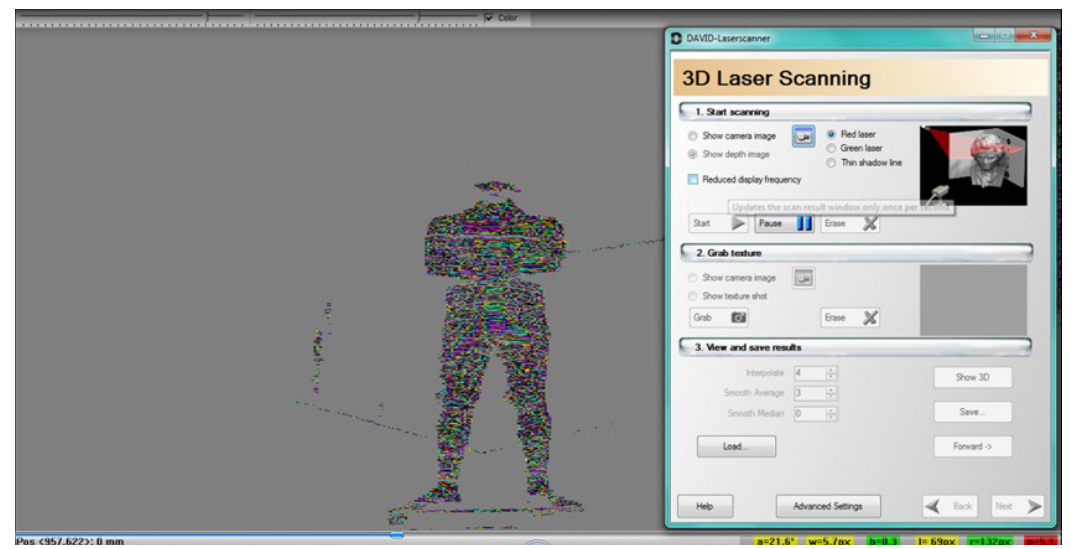

Figure 3. Construction of the 3D file while swiping the laser over the object.

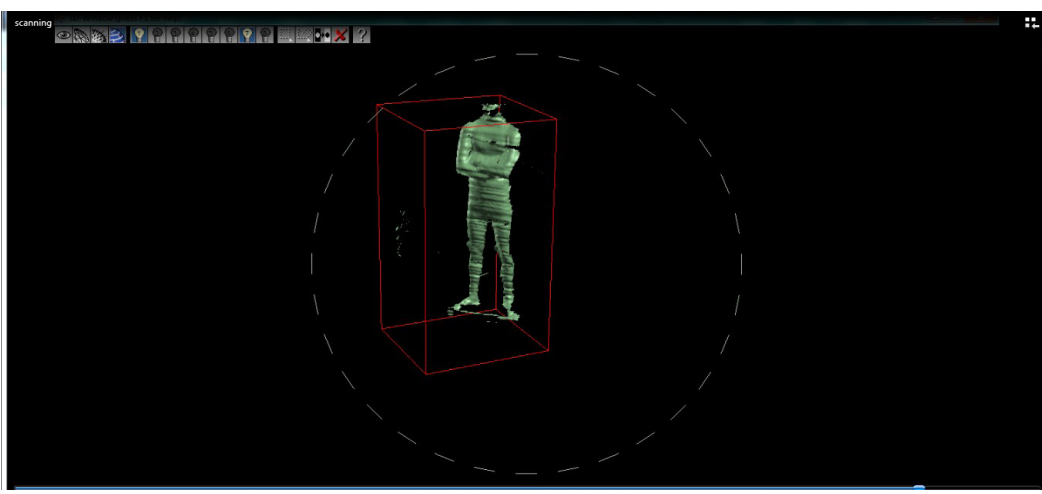

Figure 4. DAVID Laser Scanner Output File. This file can be stored in .ply and .obj formats. 
ordinates of that point in the $x, y$, and $z$ axes. The $x$-axis represents the width (i.e., the width of the shoulder), the $y$-axis represents the height (i.e., eye height), and the $z$-axis represents the depth (i.e., the depth of the chest). By clicking on a start-point and an end-point, the length, width, and depth of a limb were obtained. The results are presented in the next section.

\section{Accuracy and Precision}

Next, we evaluated the accuracy of the scanner fabricated in this study. For this purpose, an object, whose dimensions had been previously measured, was scanned with the scanner. The scanned file was imported into the Geomagic software. Then, the dimensions were extracted three consecutive times. The results are presented in the next section. In addition, 10 students from the School of Public Health were scanned with the fabricated device and a number of their body dimensions were measured with the Geomagic software. Immediately after laser scanning, the same body dimensions were measured by a traditional anthropometric method. In this study, the shoulder height, elbow height, waist height, height of the tip of the middle finger, and the chest width were measured.

\section{Human Model Clothing in Scanning Process}

The human models were wearing white clothing during the scanning process, since laser light can be absorbed by dark colors. Moreover, the clothing was tight so as to show the original body shape, but not so tight that it would reduce the size of the body, particularly in areas such as the abdomen. The physical position of the models at the time of scanning was set according to the ISO8520 standard (Figure 6).

\section{Results}

In order to verify the accuracy of the measurements of the built scanner, the square-shaped bottom of a chair was found to be $36.5 \mathrm{~cm}$ with measuring tape. Then, three successive scans of the chair were performed with no change in the position of the camera or the calibration of the scanning system. The size of the object in the three scans was respectively displayed as $36.59,36.57$, and 36.63 in the Geomagic software.

As mentioned earlier in the Methods section, after determining the landmarks on a digital 3D model of the human body, 10 different body dimensions were obtained by the same operator using the Geomagic software. The process for obtaining the dimensions was repeated three times. Table 1 shows the differences for each of the measurements. The minimum and maximum differences between the three series were $0.03 \mathrm{~mm}$ and $18 \mathrm{~mm}$, respectively. Finally, the anthropometric dimensions of the 10 participants obtained from the traditional method and the instrumental method were analyzed by a $t$ test. The results show that there are no significant differences between the measurements of the traditional method (measuring tape) and the new method (laser scanner).

The average time for each measurement was 5 minutes with our 3D laser scanner, where one minute was spent in changing the clothes to the scanning outfit, 1-2 minutes for scanning, and 2 minutes for obtaining the dimensions of the 3D model. The traditional direct method of anthropometry using a caliper to measure the 10 body dimensions required almost the same amount of time.

\section{Discussion and Conclusion}

This study was performed in order to assess the accuracy and precision of a 3D non-contact human body laser scanner that was constructed for this study. Anthropometric results from laser scanning methods are preferred to those from traditional methods due to their higher accuracy and precision. According to the results of this study (Table 1), the maximum difference between three separate measurements for the same individual was found

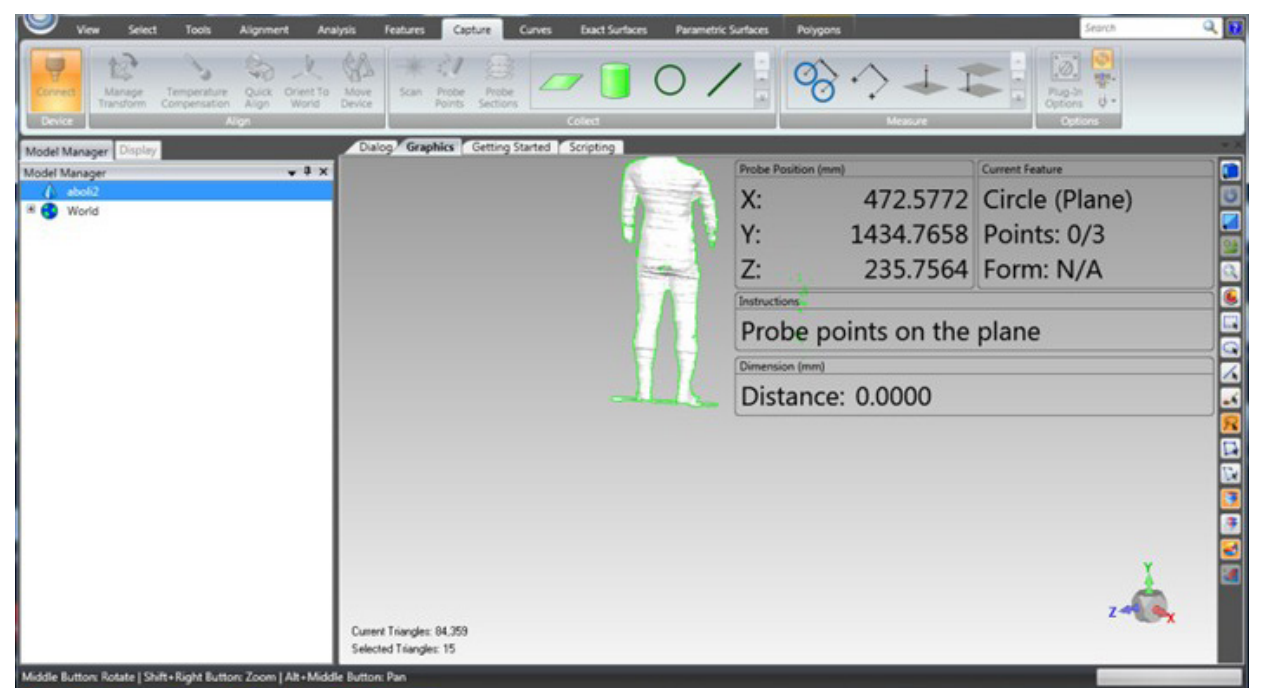

Figure 5. Geomagic Screen Shot. The file was imported into the Geomagic software so that the anthropometric dimensions could be obtained. 


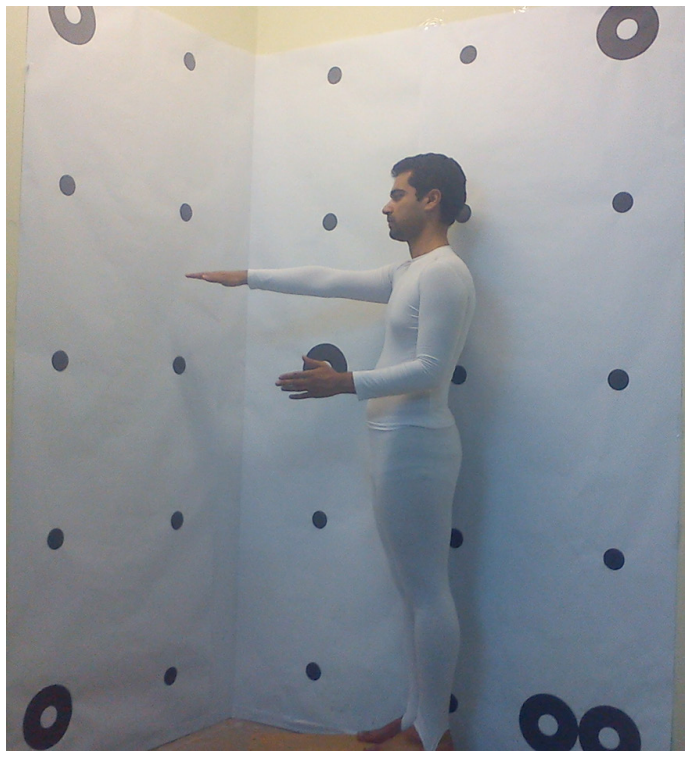

Figure 6. Physical Position of the Model at the Time of Scanning, as Per the ISO8520 Standard.

to be $18 \mathrm{~mm}$ with the Geomagic software. This difference was caused by improper recognition of the position and location of the landmarks by the operator during the measurement and the lack of familiarity working with the software. Our findings confirm the results of the study conducted by Lee et al, which compared the measurements of foot dimensions through 3D scanning and traditional methods. They showed that smaller dimensions and more points were achievable with $3 \mathrm{D}$ scanning methods than with the traditional manual methods, and the mean difference of repeated measurements was reported to be 11.9 $\mathrm{mm} .{ }^{32}$ Also, Quimby et al compared the size of computer-generated 3D models of dental molds. They reported that the errors of two operators in measuring $3 \mathrm{D}$ models ranged between 0.15 to $2.5 \mathrm{~mm}$. In order to reduce such errors, they suggested better training of the operators. ${ }^{33}$

Since zooming is available in the $3 \mathrm{D}$ image file, such zooming can affect the measurements by the user. To reduce this error when choosing the landmarks in the laser scanning method, it is better to set the zooming of the $3 \mathrm{D}$ scanner image in such a position that the landmark is easily recognized. Such errors can be reduced by appropriately training the operator with the responsibility of measuring the dimensions of the 3D human model. Moreover, improvements on the quality of scanning and installation of protrusive signs over the landmarks of the body before scanning can significantly increase the landmark identification. Rheude et $\mathrm{al}^{34}$ and $\mathrm{Marcel}^{35}$ reported that the experience and training of the operator can have an important role in reducing the errors in $3 \mathrm{D}$ measurement software packages.

In this study, we prepared a 3D image of a human model using a laser scanner built by ourselves. The dimensions of the model were obtained from the Geomagic software and compared to the actual magnitudes measured with a caliper. The accuracy of the laser scanner, with an error of less than one percent of a millimeter, was considered acceptable. Such an error is common in most studies when comparing the error rate of manual methods and computer based methods. Sohmura et al measured the dimensions of simulated dental molds with a 3D scanner and reported $0.02 \mathrm{~mm}$ differences between the actual molds and the virtual 3D models. ${ }^{36}$ Meunier and Yin showed that there were no significant differences between the anthropometric results of photographic and traditional methods. ${ }^{37}$

The $t$ test showed no significant differences between the measurements of the dimensions of 10 participants with the traditional and laser scanner anthropometric methods. In addition, the results indicated the acceptable accuracy of our scanner. Jozekanani et al showed that there were no significant differences between the measurements of feet anthropometry by a digital photography method and the traditional method, according to their $t$ test $(P>0.05)$. Also, there was no significant difference between the measurements of the 10 dimensions measured in our study by a direct traditional method and the laser scanner system (Table 2). The maximum standard deviation (SD) obtained in our study and the study by Jozekanani et al were $9 \mathrm{~mm}$ and $14 \mathrm{~mm}$, respectively. ${ }^{5}$

Table 1. Differences of the Three Measurements $(\mathrm{mm})$ in the Geomagic Software by the Same Operator

\begin{tabular}{lccc}
\hline Obtained Dimensions & $\begin{array}{c}\text { Difference of Measurements: } \\
\text { First and Third Time }\end{array}$ & $\begin{array}{c}\text { Difference of Measurements: } \\
\text { Second and Third Times }\end{array}$ & $\begin{array}{c}\text { Difference of Measurements: } \\
\text { First and Second Times }\end{array}$ \\
\hline Eye height & -0.9 & 3.8 & 5.1 \\
Shoulder height & 1.1 & 2 & -3.1 \\
Shoulder width & -13.9 & 12.9 & 1 \\
Elbow height & 0.03 & -6.6 & 6.6 \\
Width of the hips (standing) & 12.3 & -13.5 & 1.2 \\
Rump height & -8.1 & -9.9 & 18 \\
Ankle height & 2 & 5.8 & -7.9 \\
Height of the tip of the longest finger & -8.1 & -6.9 & 15 \\
Knee height & -8.6 & 10.7 & -2 \\
Height spine & 2.8 & -12.7 & 9.9 \\
\hline
\end{tabular}


Table 2. Comparison of the Measurements of 10 Bodies With the Traditional Method and the Laser Scanner

\begin{tabular}{|c|c|c|c|c|c|}
\hline Extracted Dimensions & $\begin{array}{l}\text { Method of } \\
\text { Measurement }\end{array}$ & Mean & SD & $P$ Value $^{\mathrm{a}}$ & $\begin{array}{l}\text { Difference of Mean } \\
\text { (Traditional vs. 3D) }\end{array}$ \\
\hline \multirow{2}{*}{ Eye height } & Traditional & 162.13 & 9.4 & \multirow{2}{*}{0.978} & \multirow{2}{*}{-0.07} \\
\hline & 3D scanner & 162.2 & 5.0 & & \\
\hline \multirow{2}{*}{ Shoulder height } & Traditional & 142.57 & 4.6 & \multirow{2}{*}{0.705} & \multirow{2}{*}{0.25} \\
\hline & 3D scanner & 142.32 & 5.1 & & \\
\hline \multirow{2}{*}{ Shoulder width } & Traditional & 44.52 & 2.8 & \multirow{2}{*}{0.641} & \multirow{2}{*}{-0.06} \\
\hline & 3D scanner & 44.58 & 2.6 & & \\
\hline \multirow{2}{*}{ Elbow height } & Traditional & 109.64 & 3.7 & \multirow{2}{*}{0.889} & \multirow{2}{*}{0.34} \\
\hline & 3D scanner & 109.3 & 3.5 & & \\
\hline \multirow{2}{*}{ Width of the hips (standing) } & Traditional & 31.57 & 2.2 & \multirow{2}{*}{0.767} & \multirow{2}{*}{-0.14} \\
\hline & 3D scanner & 31.71 & 2.1 & & \\
\hline \multirow{2}{*}{ Rump height } & Traditional & 97.57 & 3.2 & \multirow{2}{*}{0.646} & \multirow{2}{*}{-0.37} \\
\hline & 3D scanner & 97.94 & 3.8 & & \\
\hline \multirow{2}{*}{ Ankle height } & Traditional & 83.1 & 3.3 & \multirow{2}{*}{0.897} & \multirow{2}{*}{0.37} \\
\hline & 3D scanner & 82.73 & 3.1 & & \\
\hline \multirow{2}{*}{ Height of the tip of the longest finger } & Traditional & 63.12 & 3.7 & \multirow{2}{*}{0.929} & \multirow{2}{*}{-0.25} \\
\hline & 3D scanner & 63.37 & 3.7 & & \\
\hline \multirow{2}{*}{ Knee height } & Traditional & 54.34 & 6.7 & \multirow{2}{*}{0.756} & \multirow{2}{*}{-0.45} \\
\hline & 3D scanner & 54.79 & 5.9 & & \\
\hline \multirow{2}{*}{ Length of the spine } & Traditional & 58.26 & 2.7 & \multirow{2}{*}{0.708} & \multirow{2}{*}{0.23} \\
\hline & 3D scanner & 58.03 & 2.8 & & \\
\hline
\end{tabular}

${ }^{\mathrm{a}} t$ test.

Also, in a study conducted to compare the traditional anthropometrical method with digital imaging to evaluate the dimensions of human faces so as to determine their beauty, Omrani et al showed that there were no significant differences between the measurements of the manual and digital anthropometric methods, and that both methods could be used for the analysis of the dimensions of the human face. ${ }^{38}$

In the present study, the 3D scanning method proved to be an acceptable method. Robinette and Daanen stated that 3D scanning was more accurate than traditional methods and that the errors of the measurement tools could be controlled and reduced. ${ }^{19}$ Also, Telfer and Woodburn showed that the measurement of anthropometric foot dimensions was more effective using a 3D scanning method compared to traditional methods, and that it could be used for a greater number of samples. ${ }^{39}$

Although the amount of time spent in both methods was the same, it must be considered that factors such as the inappropriate posture of the anthropometrist and the violation of the personal space of the individual who is being measured are avoided by the laser scanning method, and that an archive of the 3D files can be built, which eliminates the need for the subject to return to the lab for subsequent studies. However, storing such big graphic files for a large population can be problematic. Furthermore, one of the advantages of the traditional method over the scanning method is that it does not require expensive equipment or deep expertise in order to measure the physical dimensions.

In the present study, a scanner was built that can be used in anthropometry engineering as its accuracy and precision can be considered acceptable. In order to improve the measuring technology in terms of scanning speed and the automatic measurement of physical dimensions, there is a need for teamwork and interdisciplinary studies.

\section{Acknowledgments}

The authors express their thanks and gratitude to Sohail Malek Ghasemi and Somayeh Malek Ghasemi who assisted in the procurement of some equipment.

This article is part of a master's thesis conducted by Ms. Akram Sadat Jafari Roodbandi. It should be noted that this project was not funded by any organization or institution and there is no conflict of interest in this article.

\section{Ethical Considerations}

The research followed the principles of the Declaration of Helsinki.

\section{Conflict of Interests}

The authors declare no conflict of interest, financial or other, exists.

\section{Reference}

1. Lu J-M, Wang M-JJ. Automated anthropometric data collection using 3D whole body scanners. Expert Syst Appl. 2008;35(1):407-414.

2. Pheasant S, Haslegrave CM. Bodyspace:Anthropometry, Ergonomics and the Design of Work. CRC Press; 2005.

3. Sadeghi F, Mazloumi A, Kazemi Z. An anthropometric data bank for the Iranian working population with ethnic diversity. Appl Ergon. 2015;48:95-103. doi:10.1016/j. apergo.2014.10.009.

4. Ben Azouz Z, Rioux M, Shu C, Lepage R. Characterizing human shape variation using 3-d anthropometric data. Vis Comput. 2006;22(5):302-314. doi:10.1007/s00371-006- 


\section{6-6}

5. Jozekanani M, Khavanin A, Mirzaee R, Rasolzadeh Y, Mansourizadeh M. Comparison of two methods for measuring a digital photography and manual. Ilam Univ Med Sci. 2007;16(3):17-21. (Persian).

6. Lacko DL, Huysmans T, Parizel PM, et al. Evaluation of an anthropometric shape model of the human scalp. Appl Ergon. 2015;48:70-85. doi:10.1016/j.apergo.2014.11.008

7. Choobineh A. Posture evaluation. Hamedan, Iran: Fanavaran; 2007. (Persian).

8. Hashemi-Nejad N, Choobineh AR, Baneshi MR, JafariRoodbandi A. Intra-observer and inter-observer reliability in direct anthropometry. Int J Occup Hyg. 2013;5(2):82-88.

9. Bruton A, Conway JH, Holgate ST. Reliability: what is it, and how is it measured? Physiotherapy. 2000;86(2):94-99. doi:10.1016/S0031-9406(05)61211-4.

10. Esme DL, Bucksch A, Beekman WH. Three-dimensional laser imaging as a valuable tool for specifying changes in breast shape after augmentation mammaplasty. Aesthetic Plast Surg. 2009;33(2):191-195. doi:10.1007/s00266-0089259-y.

11. Peiravi A, Taabbodi B. A reliable 3D laser triangulationbased scanner with a new simple but accurate procedure for finding scanner parameters. Am J Sci. 2010;6:80-85.

12. Xie $\mathrm{K}$, Zhu $\mathrm{Y}$. Interactive surgery simulation for the nose augmentation using CT data. Neural Comput Appl. 2010;19(1):61-65.

13. Cao S, Yu Q, Sanchez-Azofeifa A, Feng J, Rivard B, $\mathrm{Gu}$ Z. Mapping tropical dry forest succession using multiple criteria spectral mixture analysis. ISPRS J Photogram Remote Sensing. 2015;109:17-29. doi:10.1016/j. isprsjprs.2015.08.009.

14. Xiao W, Vallet B, Brdif M, Paparoditis N. Street environment change detection from mobile laser scanning point clouds. ISPRS J Photogram Remote Sensing. 2015;107:38-49. doi:10.1016/j.isprsjprs.2015.04.011.

15. Ali NS. Reverse Engineering of Automotive Parts Applying Laser Scanning and Structured Light Techniques [Dissertation]. Knoxville: The University of Tennessee; 2005.

16. Aboolfazli A, Mirhashemi SR, Heydari A. Comparison of different systems in the anthropometric measurements of three dimensional non-contacts. International Ergonomics Conference; Tehran, Human Factors Engineering and Ergonomics Society, Iran; 2008. (Persian)

17. Mortazavi SB, Jozekanani M, Khavanin A, et al. Foot anthropometry by digital photography method and its application in design of boots. Milit Med. 2008;10(1):6980. (Persian)

18. Yu C-Y, Lo Y-H, Chiou W-K. The 3D scanner for measuring body surface area:a simplified calculation in the Chinese adult. Appl Ergon. 2003;34(3):273-278. doi:10.1016/S00036870(03)00007-3.

19. Robinette KM, Daanen HAM. Precision of the CAESAR scan-extracted measurements. Appl Ergon. 2006;37(3):259265. doi:10.1016/j.apergo.2005.07.009.

20. Lerch T, MacGillivray M, Domina T. 3D Laser Scanning:A Model of multidisciplinary research. I Textil Apparel Technol Manag. 2007;5(4):1-22.

21. Simmons KP, Istook CL. Body measurement techniques: comparing 3D body-scanning and anthropometric methods for apparel applications. Fashion Market Manag. 2003;7(3):306-332. doi:10.1108/13612020310484852.

22. Lu J-M, Wang M-JJ, Mollard RG. The effect of arm posture on the scan-derived measurements. Appli Ergon. 2010;41(2):236-241. doi: 10.1016/j.apergo.2009.07.002.

23. Civilian American and European Surface Anthropometry Resource Project-CAESAR. http://store.sae.org/caesar/.

24. Whole Body Color 3D Scanner. Cyberware website. http:// cyberware.com/products/scanners/wbx.html.

25. Textile Clothing Technology Corporation website. http:// www.tc2.com/.

26. Telmat Industrie website. http://www.symcad.com/eng/ index.htm.

27. High-precision, fast and colored $3 \mathrm{D}$ measurement of the human body with the VITUS 3D body scanners. VITRONIC website. http://www.vitronic.de/en/bodyscanning/.

28. Wicks and Wilson, The Crowley Company website. http:// www.wwl.co.uk/.

29. Istook CL, Hwang S-J. 3D body scanning systems with application to the apparel industry. J Fashion Market Manag. 2001;5(2):120-132. doi:10.1108/EUM0000000007283.

30. Jones PR, Rioux M. Three-dimensional surface anthropometry:applications to the human body. Opt Lasers Engineer. 1997;28(2):89-117.

31. Taabodi B. Design and construction of three-dimensional shape of a surface by optical scanning machine laser triangulation [Master Thesis]. Mashhad: Ferdowsi University; 2009. (Persian).

32. Lee Y-C, Lin G, Wang M-JJ. Comparing 3D foot scanning with conventional measurement methods. J Foot Ankle Res. 2014;7(44):1-10. doi:10.1186/s13047-014-0044-7.

33. Quimby ML, Vig KWL, Rashid RG, Firestone AR. The accuracy and reliability of measurements made on computer-based digital models. Angle Orthod. 2004;74(3):298-303.

34. Rheude B, Sadowski PL, Ferriera A, Jacobson A. An evaluation of the use of digital study models in orthodontic diagnosis and treatment planning. Angle Orthod. 2005; 75:300-304.

35. Marcel TJ. Three dimensional - on - screen virtual models. Am J Orthod Dentofacial Orthop. 2001;119:666-668. doi:10.1067/mod.2001.116502.

36. Sohmura T, Kojima T, Wakabayashi K, Takahashi J. Use of an ultrahigh-speed laser scanner for constructing threedimensional shapes of dentition and occlusion. J Prost Dent. 2000;84:345-352. doi:10.1067/mpr.2000.109786.

37. Meunier P, Yin S. Performance of a 2D image-based anthropometric measurement and clothing sizing system. Appl Ergon. 2000;31(5):445-451. doi:10.1016/S00036870(00)00023-5.

38. Omrani A, Barekatain M, Hasanli E, Abdolmaleki M. Comparison of anthropometry and digital photography techniques in facial proportion analysis. J Isfahan Dent School. 2012;8 (5):453-462. (Persian).

39. Telfer S, Woodburn J. The use of 3D surface scanning for the measurement and assessment of the human foot. J Foot Ankle Res. 2010;3:19-27. doi:10.1186/1757-1146-3-19. 